\section{THE MODERN TREATMENT OF SYPHILIS.}

\section{I. THE TREATMENT OF SYPIILIS IN ITS
EARLIER STAGES.}

BY

Lieut.-Colonel T. W. GIBBARD, M.B., R.A.M.C., LCTURER ON SYPHILOLOGY, ROYAI, ARMY MEDICAI, COLLIEGF:
IN CHARGE, MILITARY HOSPITAL, ROCHESTIER IBOW, LONDON;

AND

MAJOR L. W. HARRISON, M.B., R.A.M.C., PATHOLOGIST TO THE SAME HOSPITAL.

An experience in the treatment of syphilis which extends over a considerable rumber of yeais. and has been gained under particularly favourable conditions for estimating the value of antisyphilitic remedies, has led us to certain conclusions which we think of some interest.

'T'he great advances which have been made in the riagnosis and treatment of syphilis in recent years enable us now to diagnose this disease from its earliest stages, detect its presence in the absence of nalied eye signs, and effectually control its progress. The old uncertainty of diagnosis in the primary stage has been replaced by the certainty which results from microscopical examination of the exudate from the sore; the signs of syphilis have been increased by one which is the most constant of all---the Wassermann reaction; and, thanks to salvarsan, the slow dragging progress towards recovery which was the rule under exclusively mercurial therapy, a progress which was often marked by many relapses, has given way to one which is at once more rapid and, judged by every test we can apply, more permanent.

It requires no very vivid imagination to realize what these advances mean to the control of syphilis. For ourselves, we believe that, properly used, they gire us the power to limit syphilis to its earliest stages, and eventually to abolish, amongst other curses, congenital syphilis. As a contribution to this ideal we will describe the lines on which we think syphilis should now be managed in its earlier stages.

The Importance of Early Diagnosis and Treatient

The results we have obtained with salvarsan have shown us that it is of the very greatest importance to commence treatment in the carliest possible stage-much earlier, in fact, than that in which the primary sore can be recog. nized by the naked cye. In each of the various series of cases we have treated with salvarsan on different definite plans the total relapses which followed when treatment commenced in the secondary stage were more than double those which followed when it commenced in the primary stage. A.dd to this the risk of transmission to others, either directly from the sore or through the seminal fluid, and the chances of the central nervous system becoming seriously infected during the weeks which elapse between the first appearance of the primary sore and the outbreak of secondary signs, and it must be clear that every effort should be made to cnsure that treatment commences as early as possible.

The value of a microscopic examination to the diagnosis of early syphilis does not seem to be sufficiently recognized. When a patient presents himself to his medical adviser with an early syphilitic sore, the commonest mistake which is made is to judge it by its naked-eye appearance, assume at once that it is not syphilitic because it has not the look of a Hunterian chancre, and prescribe an antiseptic ointment. Subsequently, when the sore begins to look more typical of syphilis, a blood test is thought of, a specimen of blood is sent to a pathologist, and the result not infrequently returned as doubtful or negative. Still a diagnosis is not made and more time is lost, till, finally, a positive blood reaction, or the outbreak of secondary syuptoms, makes the diagnosis clear. All this time the spirochaetes have been multiplying in the patient's tissues, and the latter have been surrounding it with barriers of new connective tissue, which mako it increasingly difficult for remedies eventually to reach the parasite. If in the first instance the surgeon had cansed a little serum to ooze from the margin of the sore by scraping it lightly with a scarifier, by rubbing it over with spirit and drying off the spirit, or by rubbing it fairly encrgetically with a dry swab, had allowed the serum to run into a capillary tube (such as is used for calf lymph), a procedure which is fully as easy as the taking of a blood specimen, and had then dispatched the specimen to a pathologist, a diagnosis in the case of syphilis would have been reached in practically every case within a few minutes of the opening of the parcel. Another mistake which is commonly made is to apply an antiseptic ointment to the sore when it is first seen, and some time later, when the sore takes on a suspicionsly syphilitic appearance, to take the specimen for microscopical examination. If by any chance an antiseptic has been applied to the sore, and the specimen lias to be posted, less time will be lost in the end if it is dressed for a few days with simple saline solution or boiled water, since the application of an antiseptic to the sore always causes the spirochaetes to retire to the deeper layers.

For over four years we have made a rule of microscopically examining the exudate from every sore, how. ever trivial and unlike syphilis it may appear, and are convinced that is impossible for anyone, however experienced he may be, to recognize a syphilitic sore in its earliest stage without the aid of the microscope. This is the stage, however, in which, as we have said, it is of prime importance to commence treatment, and it follows that the surgeon who would do the best for his patient will never neglect this method of making an early diagnosis.

By repeatedly demonstrating the certainty with which a diagnosis of syphilis can be made by means of dark. ground illumination, by enlarging on the trivial appearance of many sores in which we have demonstrated the Spirochacta pallida, and by frequently speaking in the presence of our pationts of the advantages of early treatment, we have gradually educated the soldiers under our charge to take serious notice of the merest abrasions of the penis. Certainly the microscope often reveals no spirochaetes, and later events show that the sore was non-syphilitic but, on the other hand, it is becoming more and more common for soldiers in the London District who are infected with syphilis to "report sick" when the sore is no larger than a split pea. It is worth the trouble of many negative examinations of non-syphilitic venereal sores to have the satisfaction of detecting one case in such an early stage, and commencing treatment at once. Circumstances make it, of course, easier to educate the soldier in these matters than the civilian, but we cannot help thinking that if all practitioners realized the value of an early diagnosis of syphilis and the ease with which it can be carried out, their knowledge would gradually be conveyed to the public.

In connexion with the examination of venereal sores another point may be mentioned here. Occasionally it happens that a patient is doubly infected by one exposure. A few days after exposure a soft cliancre develops in which the Spirochaeta pallida is not discovered, but the patient subsequently develops secondary syphilis. The early stages of such syphilitic infections may easily be missed if a close watch is not lept on the sore, especially at the end of two to four weeks after it has made its first appearance.

It is not nccessary to enlarge on the Wassermann test as a means of diagnosis. Of its value there can be no doubt, but the ideal treatment of syphilis commences before the Wassermann reaction is of any valuc in diagnosis, and the place of this test is properly in the subsequent observation of the patient.

\section{Treatuent.}

The diagnosis having been made on the lines suggested above, it becomes necessary to lay down a programme of treatment and to see that it is carried out.

In the following remarks we shall spcak of salrarsan rather than of neo-salvarsan, because we have chiefly worked with the older prcparation. A short experience with neo-salvarsan inclined us to the belief that it is not quite so active as salvarsan in corresponding doses, but our chief reason for adhering to salvarsan is that neo-salvarsan is more easily oxidized than salvarsan, especially at ligh 
temperatures, so that we did not think that it would be suitable for use in the tropies, and preferred to find out what could be done with a preparation which could be used wherever our soldiers serve.

It is hardly necessary now to produce further proof of the superiority of salvarsan and mercurial treatment over exclusively. nercurial treatment. This is agreed upon by practically every one who has had an opportunity of cornparing fairly the two methods, and we need only mention here the figures we produced at the International Congress of Medicine this year. 'Ihese showed that of 378 patients treated exclusively with mercury in rogular courses $83 \mathrm{per}$ cent. relapsed clinically at least once during the first year, while out of 152 patients treated with two injections of salvarsan and nine injections of mercurial cream, or three of salvarsan and four of mercurial cream, only $3.9 \mathrm{per}$ cent. relapsed clinically within a year of the suspension of treatment. Three months after the suspension of two years' regular mercurial treatment, out of 289 cases, more than 40 per cent. gave a positive reaction to the original Wassermann test, while trvelve months after the suspension of a course of treatment with salvarsan and mercury, which lasted not more than nine weeks, 19.4 per cent. gave a positive reaction.

It is of the utmost importance tbat the patient be impressed with the necessity of undergoing a thorough initial course of salvarsan and mercury, and of subse quertly submitting himself to periodical examinations. If the patient will not uudertake to submit to a thorough and definite course of salvarsan and mercurial treatment, it would probably be wiser to withhold the salrarsan, since in this case the patient would generally be compelled by a succession of reminders to prolong his treatment over what is really a critical period.

In the early stages of salvarsan treatment a large number of cases in the early primary or secondary stage received a single injection of salrarsan, which caused the rapid disappearance of all clinical symptoms. Impressed by this and believing themselves to be cured, they refused further treatment, if such was advised. A very large proportion of these cases subsequently relapsed; in other words, became infectious again, and doubtless many of then transmitted the discase to other's. Further, it is anongst these patients who received what we now linow to have been a quite inadequate amomnt of treatment that practically all the cases of cranial nerve disturbance have occurred. It lias been established by the researches of Dreyfus and other's that the meninges are infected during the early stages of syphilis in a far larger proporticn of cases than was ever imagined ( 83 per cent. according to Dreyfus), and it is clear that the first course of treatment must be calculated to prevent infection of the central nervous system. We cannot discuss here tho question of crauial nerrea; disturbances being due to salvarsan poisoning as son e hare asserted. It is sufficient to say they occur for the most part amongst patients who have received considerably less salvarsan than is usual, and that when promptly recognized and treated with salvarsan before the ncrve has become irrevocably damaged they almost invariably recover. The only two cases of the liind which we have had support these remarks, since botl of them received much less salvarsan than we are in the habit of administering.

It may be said here that it is easy to prescribe a thorough course, but it is another matter to get a free and independent patient to carry it out. We grant tliat it is a much more diffieult question with civilian patients than with military, but if the medical adviser thoroughly belieres in the truth of his advice he can clo a great deal towards making his patient carry it out.

Another question of interest is the safety to life of salvarsan injections. We consider that when due regard is paid to the precantions which we will shortly mention it is fully as justifiable to recommend a.salvarsan injection as a mercurial. No death or symptom causing any alarm has followed any of the 3,800 injections which have been given at the Military Hospital, Rochester Row. Out of some thousand injections which have bcen given at the Portobello Military Hospital, Dublin, there has been one deatl, and out of nearly 6,000 injections given by American army surgeons, one death can be attributed to salvarsan. In each of these cascs the death followed the second of tivo injections given within fourteen days of one another.
For ourselves, we think that the administration of salvarsan is safe enough to justify its reconmendation in all ordinary cases of syphilis.

Precautions in Special Cases.

There are cases in which it is advisable to proceet cautiously, and amongst these we would include all suffering from disease of the central nervous system, of the lieart, lungs, or other viscera. In these it may be necessary to commence with 0.2 to 0.3 gram salvarsan, aud so to administer the total amount of salvarsan considered necessary by meaus of a number of small injections rather than in a fow larger opes. We malke a practice of examining the urine of cvery pationt beforc injecting salvarsan, and when albumin is found ar?minister a first dose of 0.2 to 0.3 gram, according to the condition found, and repeat the dose or slightly increase it a week latcr if the first injection prodiced no untoward symptoms. Neisscr recommends that in all cases a cautious start should be made so as to make sure that one is not dealing with an idliosyncrasy to salvarsan. 'This can, of course, always be clowe provicted that in the end the patient receives in a reasonable time the total amount which is considered aclequate, but in ordinary cases of syphilis, where the patient appears to bo otherwiso lieaithy, we prefer to give the total amount of salvarsan which we consider necessary for one course in a few full ioses rather than subject the patient more frequently to the incouvenience of preparation for and the aftertreatment which an intrarenous injection. of salvarsan entails.

Considerations Concerning the Intervals between Doses.

Another question commected with the safety of salvarsan conccus the intervals of time at which full doses can be injected. It has been the practice of some surgeons to give full doses at intervals as short as forty-eiglit hours, but more and more are now advocating longer intervals than this. Quite possibly in the great majority of cases it may be safe cnough to give two injections of 0.6 gram within two days of one another, but, as far as we can judge from the literature, in practically every one of the cases in which epileptiform convulsions followed by coma and death on the fourth or fifth day after an injection has occurrel, it was after two or more full doses had been administered at an interval which was something less than fourteen days. 'The number of cases in which these symptoms, which we think must be attributed to salvarsan poisoning, hare followed the first injection must be very small, since we had bcen able to find records of only three. It scems to us, therefore, that we have to reckon with a rery occasional idiosyncrasy to salvarsan, and that this is manifester practically only when the remedy exercises a cunulative action. There is no point in rumning even the very slight risk of such a calamity as we have described if it can be avoided by sufficiently spacing out the injections, and, for reasons given below, we think that the periods between full doses of salvarsan can be lengthened to more than fourteen days without lessening the therapeutic effect if mercurial injections are given in the intervals.

\section{Preparation and After-Treatment.}

The preparation and after-treatment of patients are of some importance to the safety of salvarsan. We recom. mend the alministration of a purgative on the night before, and allow no food for four hours previous to an injection. The patient is made to rest in bed till tho following day, being allowed solid food for the first time thee to four hours after the injection, provided there is no vomiting or diarrhoea. Though he gets up on the following day, the patient is not allowed to do anything moro than lounge about. Possibly this is an cxcess of caution, but a certain proportion of patients have a slight rise of temperature on the second evening, and it is from thoso who have dined out, gone to the theatre, or otherwise dis. sipated on the sccond day that we.have had the most complaints of slight malaise and headache for a few days after the injection.

Our principle in regulating the intervals between loses is based on the following conception :

That the first full dose probably destroys every Spirochaeta pallida which it can easily reach through tl. 
circulation, but that in the midst of infiltrated areas a certain number of spirochణetes escapo complete destruction since the remedy does not reach them properly.

'That after the first injection the surviving spirochaetes remain inactive; nature begins to remove the infiltrations which resulted'from the previous activity of the parasite, and in döing so sets free the spirochaetes buried there. 'This process of repair, as is well known, takes a ferw weelss (witness the length of time the induration remains round a well-developed primary sore), and until it 'is fairly well advanced it seems to us that another dose of salvarsan is practically wasted.

That it is necessary to ensure that as these sclerosed areas arc opened up and the spirochaetes within them are-fieed the latter are allowed no headway. This we think can be done by keeping a containing force in the form of a small amount of mercury continually circulating in the blood.

Our conception may be quite wrong, but is supported by this, that in a large preportion of relapses the symptomis which characterize the relapse are an exact reproduction of those for which the patient first sought treatment. 'This is especially marked in primary cases, in which the relapse is very frequently manifested by a return of the primary sore without otlier symptoms.

\section{Plan of Course.}

Regarding the course which can be considered the minimum, it is as yet impossible to speak quite definitely, since we have not been able to devise one course which is at once the most economical and followed by no relapses. We have administered salvarsan or salvarsan and mercury on certain definite plans to successive series of cases, and have subsequently followed the progress of as many of onl patients as possible in order to determine which plan of treatment is foliowed by the sinallest proportion of relapses. The results of onr investigation on these lines lnve been published from time to time and werc read to the International Congress of Medicine this year. They dealt with the following schenes:

1. A single intramuscular injection of salvarsan.

2. Two intravenous injections of 0.6 gram salvarsan at an interval of a fortnight.

3. An intravenous injection of 0.6 gram salvarsan, followed at intervals of fourteen days by three intravenoits injections of 0.3 gram salvarsau.

4. 'Three intravenous injections of - 0.6 gram' salvarsan at-intervals of fourteen days, with four weekly injections of calomel, all within the same month.

5. An -intravenous injection of 0.3 gram salvarsan, followed by nine-mercurial injections, and lastly, an intravenous injection of 0.3 gram salvarsan.

6. An intravenous injection of 0.6 gram salvarsan, nine weekly injections of-mercurial cream, and lastly, an intravenous injection of 0.6 gram salvarsan.

7. An intravenous injection of $0.6 \mathrm{gram}$ salvarsan, five weekly injections of mercurial cream, a-second-intravenous injection of 0.6 gram salvarsan, five more mercurial injections, and lastly, an intravenous injection of 0.6 gram salvarsan.

Disregarding (5), which proved an utter faiture, the use of mercury in conjunction with full doses of salvarsan gave better results than the exclusive use of salvarsan. The last course mentioned (three salvarsan and ten mercurial injections) promises to give the best results of all, though we have not yet treated a sufficient number of cases to judge its merits fairly. This course is more intensive than one consisting of tro salvarsan and nine mercurial injections, which our tables showed to have given the best results up to date. It can, therefore; be expected to bo followed by fewer relapses, and as-it is necessary to improve on. the course of two salvarsan and nine mercurial injections, which was followed by 5 per cent. clinical and 18 per cent. Wassermann relapses within twelve. months of suspending treatment, we can only consider that for the present the minimum course should consist of three salvarsan-and ten mercurial injections distributed in the manner we have described.

In cases in which it is necessary to make a cautious start by giving 0.2 to 0.3 gram salvarsan, provided that the paticnt has shown no untoward symptoms after the first dose, we inject the balance to make up 0.6 gram within five to seven days of the first injection. When the central nervous system is obviously involved, although it is neces- sary to commence caritiously, the tótal'ámount of satrarsan administered in one course should be greater (even atote the amount) than that wliich is given in ordinary cases and the cerebro-spinal fluid should be examined at the end of the course.

In primary cases it is important to treat the sore, either by excision, cautery, or with calomel ointment. This is the order of preferencs, and the choice must depend on the site of the sore.

\section{All Cases to be Kept under Observation.}

Subsequent observation of the patient is indispensable. As a routine measure in dealing with soldicrs we excus attendance for' three months after the first course, as we have found that relapses do not occur curing this period: At the end of three months a clinical examination is made and the blood tested for the Wassermann reaction by the original and by Stern's method. 'Subsequently, in secondary cases a clinical examination is made every month, and the blood is tested every three months till the end of the first year. - In primary cases a clinical examination is made every month for three nonths, and then every thires months bill completion of the period of observation, the blood being examined every three months as in secondary cases.

Our practice during the second year varies with tho nature of the case when first treated. Primary cases are excused further attendance when the blood has continu. ously given a negative reaction, and there have been no clinical sigas for twelve months after suspension of treat ment. Secondary cases are observed at regular intervals throughout the second year. A patient is considered to have relapsed, and to require further treatment, if at any time he either shows clinical signs of syphilis or his blood serum gives a positive Wassermamn reaction.

In case of relapse, there is a temptation, especially if the only manifestation is a weakly positive Wassermann reactiou, to prescribe only a single close of salvarsan, in the hope that this, added to the previous treatment, will complete the defeat of the spirocliaete. We think tinis a mistake, and that, on the sightest sign that the disease is not eradicated, the patient should receive a course which is as strenuous as, or more strenuous than, that at firs' prescribed.

Shere is nothinard of Cure.

thing more difficult than the laying down of a standard of cure for syphilis. It is well linown that absence of clinical signs iol many years is of little value, and the Wassermann test is of too recent date to enable us to julge what reliance.we can place on a series of negative reactions.

As a rontine measure we lave adopted the standard mentioned in spealking of the observation of patientsthat is, in primary cases twelve months, and in secondary cases two years, freedom from signs, clinical or Wassermann, from the date of the last injection.

In a number of special cases, such as when the patient wished to marry at an earty date, we have given the provocative injection of a small dose of salvarsan, followed by three blood tests at intervals of two, six, and thirteen days, which has been advoeated by Gennerich and by Milian, but in only one did the previously negative serum become positive, and we have not adopted it as a routine test for cure.

\section{Scymari.}

We lrave endeavoured in the abore remarks to convey our views as to the lines on which we think early cases of syplinlis should be managed. Sammed up, they amourt to this :

1. Commence treatment in the early primary stage whenever possible.

2. Destroy the primary sore whenevor possible and insist on the patient receiving not less than three sal. varsan and ten mercurial injections in the manner described.

3. On no account neglect subsequent observation, and prescribe a definite course which is just as strenuous as in the first instance if the patient shows the least sign, clinical or Wassermann, that his disease has not boen eratlicated.

4. Be cautious about pronouncing a patient cured in any case, but certainly do not do so till he has continued froe from all signs, clinical or Wassermann, for at least a jcar 
after suspension of treatment in primary cases, and two years in seconclary cases.

The price of salvarsan and the amount of special work which such a scheme entails malse it inapplicable under present conditions to patients in poor circumstances, but it is hardly necessary to say that the control of syphilis in its earlier stages affects the lives and happiness of a sufficiently la!'ge pcrcentage of the population, present and future, to make it of national importance.

When we had to reiy on mercury, it was practically hopeless to attempt such a control, but with salvarsan, which render's the patient non-infectious so quickly, and has so markedly shortened the duration of treatment, our course, though still difficult, has bccome clearer, and it is not too much to hope now that we shall be assisted with adequate mcasures in removing a great curse from our midst.

\section{II.}

\section{THE TREATHENT OF SYPHILIS AT THE ROYAL} NAVAL HOSPITAL, CHATHAM :

Resclts DURING THE LAST Two and a Half Years, AND THE INFERENCES TO BE DRAWN FROI THEM.

By Surgeon GILbERT BODLEY SCOTT, R.N.

To those members of the medical profession who have not had much experience in the modern treatment of syphilis, and who are considering it from the practitioner's point of view, the following observations may be of value.

During the period in which $I$ was in charge of this work 1,100 cases were treated by salvarsan and neosalvarsan and 2,500 injections were given. For its proper control Wassermann reactions are necessary, and in the period mentioned over 3,000 reactions were carrich out.

'There are between 108 and 130 beds at Chatham Hospital set apart for venereal disease only. The cases come from ships, chiefly in the North Sea, and the disease is contracted at the various ports on the East Coast of Scotland and England. In addition cvery few months batches of invalids arrive from ships abroad.

Variations in Virulence.

Three points in the incidence of the disease are worth mention. Some towns produce a much more virulent infection of sypliilis than others do, and I alvays consider that the Bombay and Giblaltar infections are not only much more severe than English and Scottish, but are not so amenable to mercury. Syphilis contracted in China will produce in Europeans a very rapid and virulent form of the disease.

'This geographical factor should undoubtedly influence the initial intensity of the treatment, its duration, and the prognosis. By prognosis I do not mean danger to life, but likelihood of relapse to active dissase and a permanent positive Wassermann reaction.

\section{Extragenital InFEction.}

The treatment of extragenital chancres is influenced in the same manner. I have found that the fingers and lips are the most fu'equent sites.

Naval medical offizers thoroughly realize the danger of lip infection on board ship, and men liable to pass on the infection are segregated in the sick-bay or sent to hospital.

Were this precaution not taken lip chancres would be far more frequent. It is just as necessary to instruct syphilitic patients in the prevention of the spread of disease as it is the tubercilous. The old stone fountain and cliained drinling cup must have caused in hot weather many cases of syphilis and other communicable diseases. The prevention of finger chancres lies not with the re moval of offending nails, splinters of wood, and other excuses, but in injproving the morals of man.

\section{Diagrosis.}

The early diagnosis of syphilis is of vast importance, and the bearing on the treatment, the prognosis, and the patient's life is not yet properly realized by three-quarter of the medical profession and not at all by the public.
If there is to be no return to the Contagious Diseases Act of 1864, then the abolition of the lidden plague in relation to syphilis must still lie in the treatment of men and women immcdiately they become sources of danger. Early diagnosis and treatmerst must go hand in hand, and to carry out this ideal successfully some kind of institution analogous to the tuberculin dispensary must be forned.

Importance of Early Diagnosis.

I will talse the subject of early diagnosis first and summarize beforehand what I am going to say.

1. For our purpose the diagnosis by the Wassermanr reaction is practically useless.

2. The only useful means of cliagnosis of early syphilis is the demonstration of the Spirochacta pallida.

I am firmly convinced that if all cases of syphilis were examined in the fir'st stage of the clisease, and in the first ferv days of that stage, before antiseptics have been applied, the spirochacte could and would be easily found.

I am also firmly convinced, although I cannot give definite proof, that if these early cases are treated by two or three-injections of salvarsan or neo-salvarsan and a short course of mercury, 99 per ccnt. of these will b3 cured.

When once the Wassermann reaction lias become positive or the sore hard and indurated this treatment will not cure more than 60 per ccut., and I should remain doubtful of that 60 for the next fiftecn years.

If, however, a prolonged course of mercury-two to three years, with intermissions-is gircn to these cases in corjunction with salvarsan, a better outlook is obtaincl.

Not many years ago we allowed our patients to reach the secondary stage beforc we made a diagnosis and treated them. What would be said if we to-day waited to see if secondary deposits of cancer occurred in the liver in a suspected case of epithelioma of the lip), or a tumour in the region of the appendix to burst before diagnosing an abscess?

It sounds luclicrous, but it is really not more absurd than at the present day to wait for a positive Wassermann reaction or secondary symptoms. I am of the opinion that when once a man has developed secondary syphilis at least 60 per cent. of his chances of being cured have gone. When the disease has been established for a year I do not believe thcre are more than 20 per cent. in whom a curc is effected or in rwhom the infection dies out. I except from this statement McDonagh's method of treatment, because I have had no practical experience of its results and am not qualified to give an opinion. Why should we condemn our patients to such a poor outlook when early diagnosis and treatment give such a good one?

Demonstration of the Spirochacte.

The diagnosis of early syphilis by demonstration of the spirochaete is easier than examining for tubercle bacilli in the sputum.

The methods are two: (1) By Chinoseink; (2) by the dark-ground illumination. Both these methods are de. scribed in any book dealing with laboratory work, but a laboratcry is not required, only the most simple apparatus, a microscope, and cxperience in recognizing the various forms of spirochaete.

If we do not get our patients in this early stage these methods are still casily employed, provided that no antiseptic has been applied to the sore, and that it is not a healing one.

Under these two latter conditions a diagnosis must be made from its character or by Wassermann's reaction. A hard indurated sore, if not malignant, is almost certainly syphilitic. $A$ soft shallow one more often turns out to bo syphilis than "chancroid." Therefore, the nature of a soft sore cannot be cliagnosed by its appearance.

\section{Date of Wassermann's Reaction.}

Wassermann's reaction becomes positive about three to four weels after the appearance of the sore in most cases. Sometimes it is earlicr, sometimes later. I refer here to reactions dome by Floming's method, or the original when using cholesterin antigen.

The appearance of the reaction probably means that the infection has passed beyond the local stage, that it is 